ORIGINAL ARTICLE

\title{
Functional polymorphisms in cell death pathway genes FAS and FASL contribute to risk of lung cancer
}

\author{
X Zhang, X Miao, T Sun, W Tan, S Qu, P Xiong, Y Zhou, D Lin
}

J Med Genet 2005;42:479-484. doi: 10.1136/jmg.2004.030106

See end of article for authors' affiliations

.....................

Correspondence to:

Dr D Lin, Department of

Etiology and

Carcinogenesis, Cancer

Institute, Chinese Academy

of Medical Sciences,

Beijing 100021, People's

Republic of China; dlin@

public.bta.net.cn

Received

16 December 2004

Revised version received

24 January 2005

Accepted for publication

26 January 2005
Background: The FAS and FASL system plays a key role in regulating apoptotic cell death and corruption of this signalling pathway has been shown to participate in immune escape and tumorigenesis. There is reduced expression of FAS but elevated expression of FASL in many types of human cancers including lung cancer. We recently reported an association between functional polymorphisms in FAS $(-1377 G \rightarrow A)$ and FASL $(-844 \mathrm{~T} \rightarrow \mathrm{C})$ and risk of oesophageal cancer.

Objective: To examine the contribution of these polymorphisms to risk of developing lung cancer. Methods: Genotypes of 1000 lung cancer patients and 1270 controls were analysed by PCR based restriction fragment length polymorphism. Associations with risk of lung cancer were estimated by logistic regression.

Results: Compared with non-carriers, there was a 1.6 fold excess risk of developing lung cancer for carriers of the FAS - 1377AA genotype (odds ratio (OR) 1.59, 95\% confidence interval (CI) 1.21 to 2.10; $\mathrm{p}=0.001$ ), and 1.8 fold excess risk (OR $1.79,95 \% \mathrm{Cl} 1.26$ to $2.52 ; \mathrm{p}=0.001$ ) for carriers of FASL $-844 C C$. Gene-gene interaction of FAS and FASL polymorphisms increased risk of lung cancer in a multiplicative manner (OR for the carriers of both FAS - 1377AA and FASL -844CC genotypes 4.18, $95 \% \mathrm{Cl} 2.83$ to 6.18). Gene-environment interaction of FAS or FASL polymorphism and smoking associated with increased risk of lung cancer was also found.

Conclusion: These results are consistent with our initial findings in oesophageal cancer and further support the hypothesis that the FAS and FASL triggered apoptosis pathway plays an important role in human carcinogenesis.
A poptosis is involved in a variety of physiological functions, such as regulating cell numbers and eliminating unwanted or potentially dangerous cells during the development of organisms, as well as in some pathological processes, including immune disorders and tumour development. ${ }^{2}$ One of the most important advances in basic cancer research in past decades was the realisation that apoptosis and the genes that control it have a profound effect on the malignant phenotype. It has been shown that some tumour cells successfully develop either by having the ability to resist apoptotic stimuli or by inducing apoptosis of tumour specific lymphocytes..$^{3-5}$

FAS, a cell surface receptor, plays a crucial role in apoptotic signalling in many cell types. ${ }^{67}$ This receptor interacts with its natural ligand (FASL), a member of the tumour necrosis factor superfamily, to initiates the death signal cascade, which results in apoptotic cell death. ${ }^{48}$ FAS receptor is widely expressed in a variety of tissues, whereas the expression of FASL is restricted to the cells within immune system, such as activated T cells and natural killer cells, and the cells within immune privileged areas, such as the eye and reproductive organs. However, reduced expression of FAS and/or increased expression of FASL have been detected in many types of human cancer, including lung cancer, and appears to be a feature of the malignant phenotype, ${ }^{9-14}$ suggesting that the FAS/FASL system may play an important role in cancer formation. There is strong evidence demonstrating that decreased expression of FAS may protect transformed cells from elimination by anti-tumour immune responses, but heightened expression of FASL may increase the ability of tumour cells to counterattack the immune system by killing FAS sensitive lymphocytes and therefore contribute to cancer development. ${ }^{4}{ }^{10}{ }^{14-17}$ Furthermore, functional germline and somatic mutations in the FAS gene and perhaps also in the FASL gene that impair apoptotic signal transduction are associated with susceptibility to cancers, including lung cancer. ${ }^{18-22}$

Single nucleotide polymorphisms have been identified in the promoter region of the FAS and FASL genes. ${ }^{23-25}$ It has been shown that a $\mathrm{G} \rightarrow \mathrm{A}$ transition at position -1377 and an $A \rightarrow G$ transition at position -670 in the promoter region of FAS destroy stimulatory protein ( $\mathrm{Sp}$ ) 1 and signal transducer and activator of transcription (STAT) l protein binding element, respectively, and thus diminish promoter activity and decrease FAS expression. ${ }^{23}{ }^{24}$ In FASL, a T $\rightarrow$ C transition at position -844 in the promoter region has been reported to be located in a binding motif for another transcription factor, CAAT/enhancer binding protein $\beta .^{25}$ Higher basal expression of FASL is significantly associated with the FASL $-844 \mathrm{C}$ allele compared with the $-844 \mathrm{~T}$ allele. ${ }^{25}$ Because of the role that FAS and FASL play in carcinogenesis and cancer progression and because of their aberrant expression in various types of cancer, we hypothesised that these functional polymorphisms in FAS and FASL might have an impact on cancer susceptibility attributable to the reduced expression of FAS and/or the increased expression of FASL. Recently, we examined this hypothesis in oesophageal squamous cell carcinoma (SCC) and found that these polymorphisms in the promoter region of FAS and FASL were associated with the development of oesophageal SCC in a Chinese population. ${ }^{26}$ In addition, the effect of FAS and FASL polymorphisms on risk of oesophageal SCC displayed a

Abbreviations: FASL, FAS ligand; PCR-RFLP, polymerase chain reaction based restriction fragment length polymorphism; SCC, squamous cell carcinoma; Sp, stimulatory protein; STAT, signal transducer and activator of transcription 
multiplicative gene-gene interaction and appeared to correlate with tobacco smoking. ${ }^{26}$

Lung cancer is one of the most common cancers in many countries. During the past two decades, the rates of incidence and mortality of lung cancer in China have been increasing significantly and constantly. ${ }^{27}$ Tobacco smoking is the major cause of lung cancer, and the increasing incidence of smoking has been suggested to be the major factor underlying the increasing trend in lung cancer mortality in China. ${ }^{27-29}$ However, the smoking habit among Chinese women is rare; nationwide surveys showed that the prevalence of smoking among women aged 15-24 years was 0.5\% both in 1984 and in 1996. ${ }^{29}$ Despite this, the mortality rates from lung cancer in Chinese women are relatively high, ${ }^{30}$ which has emphasised the impact of another aetiological factor, such as exposure to environmental tobacco smoke and indoor air pollution derived from Chinese style cooking and/or coal burning. ${ }^{31}{ }^{32}$ However, although risk of lung cancer is conclusively associated with tobacco smoke and perhaps indoor air pollution, only a proportion of exposed individuals develop the cancer in their life span, suggesting that there may be important genetic basis rendering such individuals more susceptible to the disease.

This paper describes a case-control study that aimed to examine the contribution of aforementioned FAS and FASL polymorphisms to the risk of lung cancer. We genotyped 1000 patients with primary lung cancer and 1270 healthy controls, and found that the FAS and FASL polymorphisms are associated with the risk of lung cancer.

\section{MATERIALS AND METHODS Study subjects}

This study consisted of 1000 patients with primary lung cancer and 1270 healthy controls. All subjects were unrelated Han Chinese and residents in Beijing and the surrounding regions. Characteristics of the study subjects have been described previously. ${ }^{33}$ All incident patients, who were histopathologically confirmed and previously untreated (by radiotherapy or chemotherapy), were consecutively recruited from 20 January 1997 to 20 June 2002 at the Cancer Hospital, Chinese Academy of Medical Sciences. Of the 1000 patients, 26 were newly recruited because DNA samples from 26 patients used in the previous study were no longer available. The exclusion criteria included previous cancer, metastasised cancer from other organs, previous radiotherapy, or chemotherapy. Controls were randomly selected from a pool of cancer free subjects recruited from a nutritional survey conducted in the same region during the same period as case collection. The selection criteria for controls included no individual history of cancer, and sex and age ( 5 years) matching to patients. In this study, we also selected 270 more controls from the same database matched to cases as described above, for a total of 1270 controls, to increase statistical power. Smokers were considered current smokers if they smoked up to l year before the date of cancer diagnosis or the date of the interview for controls. Nonsmokers were defined as subjects who had smoked $<10$ cigarettes in their lifetime. Information was collected on the number of cigarettes smoked per day, the age at which the subjects started smoking, and the age at which ex-smokers stopped smoking. At recruitment, written informed consent was obtained from each subject, and each participant was then interviewed to collect detailed information on demographic characteristics and lifetime history of tobacco use. This study was approved by the institutional review board.

\section{Polymorphism analysis}

Genomic DNA from controls and most of the patients was extracted from the leukocyte pellet obtained from buffy coat in each blood sample, obtained by centrifugation of $2 \mathrm{ml}$ whole blood. Approximately $25 \%$ of the DNA samples from patients was isolated from surgically resected normal tissues adjacent to the tumour of lung cancer patients. All patients and controls were genotyped using PCR based restriction fragment length polymorphism (PCR-RFLP) methods as described previously. ${ }^{26}$ A $10 \%$ masked, random sample of subjects was tested twice by different researchers, and the results were concordant for all of the masked duplicate sets.

Because the FAS - 1377G/A and -670G/A polymorphisms are in almost complete linkage disequilibrium in our study population, ${ }^{26}$ only the $-1377 \mathrm{G} / \mathrm{A}$ polymorphism was analysed for FAS in this study. The PCR primers for amplification of the FAS promoter region containing $-1377 \mathrm{G} / \mathrm{A}$ were $5^{\prime}$ TGTGTGCACAAGGCTGGCGC and 5'-TGCATCTGTCACTGC ACTTACCACCA, which produce a $122 \mathrm{bp}$ fragment. In order to induce a restriction endonuclease site, we changed the 3' end of the reverse primer from CAC to CGC, which created a BstuI cutting site. For amplification of the FASL promoter region containing $-844 \mathrm{~T} / \mathrm{C}$ site, we used the primer pair of 5'-CAGCTACTCGGAGGCCAAG and 5'GCTCTGAGGGGAGAGACCAT, which generates a $401 \mathrm{bp}$ fragment. Amplification of these two DNA fragments was accomplished separately under the same conditions, in a $25 \mu \mathrm{l}$ reaction mixture consisting of $\sim 100 \mathrm{ng}$ template DNA, $0.5 \mu \mathrm{mol} / \mathrm{l}$ each primer, $0.2 \mathrm{mmol} / \mathrm{l} \mathrm{dNTP}, 2.0 \mathrm{mmol} / \mathrm{l} \mathrm{MgCl}_{2}$, and 1.0 U of Taq DNA polymerase with $1 \times$ reaction buffer (Promega, Madison, WI, USA). The reaction was carried out in the following conditions: an initial melting step of 2 minutes at $94^{\circ} \mathrm{C}$, followed by 35 cycles of 30 seconds at $94^{\circ} \mathrm{C}, 30$ seconds at $62^{\circ} \mathrm{C}$, and 45 seconds at $72^{\circ} \mathrm{C}$, and a final elongation step of 7 minutes at $72^{\circ} \mathrm{C}$.

The restriction enzymes BstuI and BsrDI (New England Biolabs Inc., Beverly, MA, USA) were used to distinguish the FAS - 1377G/A and FASL - 844T/C polymorphisms, respectively. The restriction products were separated on $2.5 \%$ agarose gel with ethidium bromide. The RFLPs of the two polymorphisms were readily discerned. After digestion with BstuI, the FAS - 1377G allele generated $104 \mathrm{bp}$ and $18 \mathrm{bp}$ fragments whereas the variant $-1377 \mathrm{~A}$ allele generated a single 122 bp fragment. The FASL $-844 \mathrm{C}$ allele had a BsrDI restriction site that resulted in two bands $(233 \mathrm{bp}$ and $168 \mathrm{bp}$ ), and the $-844 \mathrm{~T}$ allele lacked the BsrDI restriction site, producing a single $401 \mathrm{bp}$ band.

\section{Statistical analysis}

Pearson's $\chi^{2}$ test was used to examine differences in demographic variables, smoking, and distributions of FAS $-1377 \mathrm{G} / \mathrm{A}$ and $F A S L-844 \mathrm{~T} / \mathrm{C}$ between patients and controls. The associations between the polymorphisms and risk of developing lung cancer were estimated by odds ratios (ORs) and their 95\% confidence intervals (CIs), which were calculated by unconditional logistic regression. For smokers, pack year value was calculated to indicate cumulative cigarette dose $($ pack years $=($ cigarettes $/$ day $\div 20) \times$ years of smoking). Light and heavy smokers were categorised by median pack year value of the controls-that is, $\leqslant 20$ pack years and $>20$ pack years. Because only 22 patients and 64 controls were ex-smokers, they were combined with current smokers for analysis. All ORs were all adjusted for age, sex, and smoking status or pack years, as appropriate. All statistical tests were two sided tests. We tested the null hypotheses of additive and multiplicative gene-gene and gene-smoking interactions, and evaluated the departures from additive and multiplicative interaction models ${ }^{34}$ by including main effect variables and their product terms in the logistic regression model. All analyses were performed using Statistical Analysis System software (version 6.12; SAS Institute, Cary, NC, USA). 


\section{RESULTS}

Table 1 shows distributions of select characteristics of study subjects by case-control status. The patients and controls appeared to be adequately matched for sex and age. The proportions of men and women were almost the same among patients and controls $(73.5 \%$ and $26.5 \% \vee 72.3 \%$ and $27.7 \%$; $\mathrm{p}=0.535)$. The age distribution of patients was not significantly different from that of controls $(p=0.643)$. As expected, smokers were over-represented in patients compared with controls $(65.5 \% \vee 50.8 \%$; $<<0.0001)$. Furthermore, $70.8 \%$ smokers in patients smoked $>20$ pack years that was significantly higher than that in controls $(52.7 \%$; $<<0.0001)$. Of the 1000 patients with lung cancer, 448 (44.8\%) were SCC, $297(29.7 \%)$ were adenocarcinoma, and 255 (25.5\%) were other types of lung cancer, including undifferentiated cancer $(n=90)$, bronchioalveolar carcinoma $(n=90)$, small cell carcinoma $(n=24)$, and mixed cell carcinoma $(n=51)$.

The genotyping results are shown in table 2 . The allelic frequencies for FAS - 1377A and FASL $-844 \mathrm{C}$ were 0.339 and 0.694 in controls compared with 0.371 and 0.774 in patients, respectively. The observed genotype frequencies of FAS - 1377G/A and FASL - 844T/C polymorphism among controls and patients conformed to the Hardy-Weinberg equilibrium ( $p>0.05$; respectively). Frequencies for the FAS - 1377GG, GA, and AA genotypes in patients differed significantly from those in controls $\left(\chi^{2}=14.09 ; \mathrm{p}=0.001\right)$, with the frequency of homozygous AA genotype being significantly higher in patients than that in controls $(15.4 \% v 10.2 \% ; p=0.001)$. The difference in genotypic frequencies at the FASL $-844 \mathrm{~T} / \mathrm{C}$ site-that is, $-844 \mathrm{TT}, \mathrm{TC}$, and $\mathrm{CC}$, between patients and controls was also statistically significant $\left(\chi^{2}=43.31\right.$; $\mathrm{p}<0.0001$ ), with the homozygous CC genotype being more prevalent among patients than that among controls $(61.2 \% \mathrm{v}$ $47.3 \%$; $<<0.0001)$. Multivariate logistic regression analyses showed that the FAS - 1377AA genotype carriers had a 1.6 fold excess risk for developing lung cancer compared with the FAS - 1377GG genotype carriers (adjusted OR 1.59, 95\% CI 1.21 to 2.10 ). Similarly, the FASL -844CC genotype carriers also had increased risk for the cancer compared with the FASL -844TT genotype carriers (adjusted OR 1.79, 95\% CI 1.26 to 2.52 ). However, both heterozygous genotypes for FAS and FASL polymorphisms were not associated with elevated

Table 1 Distributions of select characteristics by casecontrol status

\begin{tabular}{|c|c|c|c|c|c|}
\hline \multirow[b]{2}{*}{ Variable } & \multicolumn{2}{|c|}{$\begin{array}{l}\text { Patients } \\
(n=1000)\end{array}$} & \multicolumn{2}{|c|}{$\begin{array}{l}\text { Controls } \\
(n=1270)\end{array}$} & \multirow[b]{2}{*}{ p value* } \\
\hline & $\mathbf{n}$ & $\%$ & $\mathbf{n}$ & (\%) & \\
\hline Sex & & & & & 0.535 \\
\hline Male & 723 & 72.3 & 933 & 73.5 & \\
\hline Female & 277 & 27.7 & 337 & 26.5 & \\
\hline Age (years) & & & & & 0.643 \\
\hline$\leqslant 50$ & 248 & 24.8 & 327 & 25.8 & \\
\hline $51-60$ & 330 & 33.0 & 440 & 34.6 & \\
\hline $61-70$ & 320 & 32.0 & 386 & 30.4 & \\
\hline$>70$ & 102 & 10.2 & 117 & 9.2 & \\
\hline Smoking status & & & & & $<0.0001$ \\
\hline Nonsmoker & 350 & 34.5 & 625 & 49.2 & \\
\hline Smoker & 650 & 65.5 & 645 & 50.8 & \\
\hline $\begin{array}{l}\text { Smoking level } \\
\text { (pack years) }\end{array}$ & & & & & $<0.0001$ \\
\hline$\leqslant 20$ & 190 & 29.2 & 305 & 47.3 & \\
\hline$>20$ & 460 & 70.8 & 340 & 52.7 & \\
\hline \multicolumn{6}{|l|}{ Histological type } \\
\hline $\mathrm{SCC}$ & 448 & 44.8 & & & \\
\hline Adenocarcinoma & 297 & 29.7 & & & \\
\hline Othert & 255 & 25.5 & & & \\
\hline
\end{tabular}

*Two sided $\chi^{2}$ test. †Includes 90 undifferentiated cancers, 90 bronchioalveolar carcinomas, 24 small cell carcinomas (SCC), and 51 mixed cell carcinomas. risk of the cancer, suggesting a possible recessive effect of the polymorphisms in these two genes. Age, sex, and smoking status had little effect on the risk of lung cancer associated with the FAS or FASL genotypes (table 2).

Because FAS and FASL are receptor/ligand system and work together in apoptotic cell death, we examined whether there was a statistical interaction between the polymorphism in FAS and in FASL that was associated with the risk of lung cancer. As the heterozygous genotypes of both FAS and FASL genes were not associated with risk of lung cancer, these genotypes were incorporated into the corresponding wildtype genotype (FAS - 1377GG or FASL -844TT) as the reference group for analysis (table 3 ). It was found that patients carrying the FASL -844CC genotype were more likely to carry FAS - 1377AA than were controls $(10.0 \% \vee 3.5 \%$; $\mathrm{p}<0.0001)$. The adjusted OR for the presence of one FAS -1377AA genotype or one FASL -844CC genotype was 1.11 (95\% CI 0.76 to 1.62 ) or 1.64 (95\% CI 1.36 to 1.97 ), respectively, compared with the lack of such a genotype. However, the adjusted OR for subjects carrying both FASL $-844 \mathrm{CC}$ and FAS - 1377AA genotypes increased to 4.18 (95\% CI 2.83 to 6.18 ; $\mathrm{p}<0.001$, test for homogeneity) compared with those who lacked both genotypes. These results indicate that there is a more than multiplicative interaction between the FASL -844CC and FAS - 1377AA genotype that is associated with elevated risk of developing lung cancer. ${ }^{34}$

Tobacco smoking is a well known environmental aetiological factor for lung cancer and has been shown to influence FAS/FASL expression; ${ }^{35} 36$ we therefore investigated geneenvironment interaction between the polymorphisms and smoking (table 4). We observed that the FAS - 1377AA genotype compared with the GG or GA genotype was not associated with increased risk of lung cancer among nonsmokers (OR 1.23, 95\% CI 0.83 to 1.81 ; p = 0.306). However, this variant genotype was significantly associated with a twofold increased risk of lung cancer in smokers (OR 2.12, $95 \%$ CI 1.46 to $3.07 ; \mathrm{p}<0.001)$. When smoking was additionally stratified by pack year value, the increased risk of lung cancer associated with the - 1377AA genotype appeared to be more pronounced in light (OR 2.92, 95\% $\mathrm{CI}=1.51$ to 5.66 ) than in heavy smokers (OR $1.84,95 \% \mathrm{CI}$ 1.18 to 2.89). In contrast, although the FASL $-844 \mathrm{CC}$ genotype was significantly associated with increased risk of lung cancer both in smokers and non-smokers compared with the TT or TC genotype, the risk seemed to be higher in heavy (OR $1.96,95 \%$ CI 1.45 to 2.64 ) than in light smokers (OR $1.37,95 \%$ CI 0.94 to 1.98 ).

We also compared the risk of lung cancer associated with the FAS and FASL polymorphisms among different subtypes-that is, SCC, adenocarcinoma, and other histological types of lung cancer. No statistically significant differences in terms of risk associated with the FAS - 1377AA genotype or FASL - 844CC genotype were found among histological types of lung cancer and the increased risk was consistently observed in all subtypes of the cancer (table 4).

\section{DISCUSSION}

In the previous study, we reported that the $F A S-1377 \mathrm{G} / \mathrm{A}$ or $-670 \mathrm{~A} / \mathrm{G}$ and FASL $-844 \mathrm{~T} / \mathrm{C}$ polymorphisms were significantly associated with increased risk of oesophageal SCC in a Chinese population. ${ }^{26}$ Because aberrant expression of FAS and/or FASL has been detected in lung cancer, ${ }^{12-14}$ and germline and somatic mutations in the FAS and FASL genes are associated with a high risk of cancers, ${ }^{18-22}$ we investigated whether functional polymorphisms in FAS and FASL could affect the risk of lung cancer development. We analysed 1000 patients with lung cancer and 1270 healthy controls, and found that the FAS - 1377AA and FASL -844CC genotypes were statistically significantly associated with increased risk 
Table 2 Genotypic and allelic frequencies of FAS and FASL in patients and controls and their associations with the risk of lung cancer

\begin{tabular}{|c|c|c|c|c|}
\hline Genotype & $\begin{array}{l}\text { Controls } \\
(n=1270) n(\%)\end{array}$ & $\begin{array}{l}\text { Patients } \\
(n=1000) n(\%)\end{array}$ & Crude OR* $(95 \% \mathrm{Cl})$ & $\begin{array}{l}\text { Adjusted ORt } \\
(95 \% \mathrm{Cl})\end{array}$ \\
\hline \multicolumn{5}{|l|}{ FAS - 1377G/A } \\
\hline GG & $539(42.5)$ & $413(41.3)$ & 1.00 (reference) & 1.00 (reference) \\
\hline GA & $601(47.3)$ & $433(43.3)$ & $0.94(0.78$ to 1.13$)$ & 0.94 (0.78 to 1.14$)$ \\
\hline AA & $130(10.2)$ & $154(15.4)$ & $1.55(1.17$ to 2.04$)$ & $1.59(1.21$ to 2.10$)$ \\
\hline $\begin{array}{l}\text { A allele frequency } \\
\text { FASL - } 844 T / C\end{array}$ & 0.339 & 0.371 & & \\
\hline $\begin{array}{l}\text { FASL - } \\
\pi\end{array}$ & $109(8.6)$ & $64(6.4)$ & 1.00 (reference) & 1.00 (reference) \\
\hline TC & $560(44.1)$ & $324(32.4)$ & 0.99 (0.69 to 1.40$)$ & $1.00(0.71$ to 1.42$)$ \\
\hline & $601(47.3)$ & $612(61.2)$ & 1.73 (1.23 to 2.44$)$ & 1.79 (1.26 to 2.52$)$ \\
\hline $\mathrm{C}$ allele frequency & 0.694 & 0.774 & & \\
\hline
\end{tabular}

*Data were calculated by unconditional logistic regression, and tadjusted for sex, age, smoking status, and other genotype where appropriate. OR, odds ratio; $\mathrm{Cl}$, confidence interval.

of lung cancer. In addition, the association between these two polymorphisms and the risk of lung cancer displayed a multiplicative gene-gene interaction, which rendered the subjects having both FAS -1377AA and FASL -844CC genotypes at much higher risk for developing lung cancer. Moreover, we observed a statistically significant interaction between the polymorphisms and tobacco smoking. Another interesting finding in the present study was that the increased risk associated with FAS and FASL polymorphisms was similar in different subtypes of lung cancers, suggesting that these polymorphisms might be general risk factors for common cancers. These results are consistent with our previous findings from oesophageal $\mathrm{SCC}^{26}$ and further support the hypothesis that the FAS and FASL triggered apoptosis pathway plays an important role in human carcinogenesis.

Previous studies have shown that the investigated FAS $-1377 \mathrm{G} / \mathrm{A}$ and FASL -844T/C polymorphisms are functionally significant. The $F A S-1377 \mathrm{G} \rightarrow \mathrm{A}$ transition is located within an Spl transcriptional factor binding site in the promoter region of FAS. ${ }^{23}{ }^{24}$ Because the $-1377 \mathrm{~A}$ allele has a significantly reduced ability to bind Spl, an important and ubiquitously expressed transcriptional activator, ${ }^{37}$ decreased FAS expression associated with the -1377AA genotype is expected. ${ }^{23}{ }^{24}$ The FASL $-844 \mathrm{~T} \rightarrow \mathrm{C}$ mutation is also located in the promoter region of FASL, and the $-844 \mathrm{C}$ allele has been shown to have significantly higher promoter activity and basal FASL expression compared with the $-844 \mathrm{~T}$ allele. ${ }^{25}$ These findings strongly support our molecular epidemiological observation that the FAS - 1377AA and/or FASL -844CC genotype is associated with significantly increased risk of lung cancer. Because the FAS/FASL system plays an important role in apoptosis and cancer development, it may

Table 3 Risk of lung cancer associated with FAS genotypes by FASL genotypes among patients and controls

\begin{tabular}{|c|c|c|c|c|}
\hline \multicolumn{2}{|c|}{ Genotypes } & \multirow[b]{2}{*}{$\begin{array}{l}\text { Patients, } \\
\text { n (\%) }\end{array}$} & \multirow[b]{2}{*}{$\begin{array}{l}\text { Controls, } \\
\text { n (\%) }\end{array}$} & \multirow[b]{2}{*}{$\mathrm{OR}^{*}(95 \% \mathrm{Cl})$} \\
\hline $\begin{array}{l}\text { FASL } \\
-844\end{array}$ & $\begin{array}{l}\text { FAS } \\
-1377\end{array}$ & & & \\
\hline$\pi+\mathrm{TC}$ & $G G+G A$ & $334(33.4)$ & $584(46.0)$ & $\begin{array}{l}1.00 \\
\text { (referent) }\end{array}$ \\
\hline$\pi+\mathrm{TC}$ & AA & $54(5.4)$ & $85(6.7)$ & $\begin{array}{l}1.11 \\
(0.76 \text { to } 1.62)\end{array}$ \\
\hline $\mathrm{CC}$ & $G G+G A$ & $512(51.2)$ & $556(43.8)$ & $\begin{array}{l}1.64 \\
(1.36 \text { to } 1.97)\end{array}$ \\
\hline $\mathrm{CC}$ & AA & $100(10.0)$ & $45(3.5)$ & $\begin{array}{l}4.18 \\
(2.83 \text { to } 6.18)\end{array}$ \\
\hline
\end{tabular}

*Data were calculated by unconditional logistic regression, adjusting for sex, age, and smoking status. OR, odds ratio; $\mathrm{Cl}$, confidence interval. be expected that individuals who carry the FAS - 1377AA and/or FASL -844CC genotype, thus having decreased expression of FAS and/or increased expression of FASL over a lifetime, are at high risk of developing lung cancer. Supporting evidence also comes from association studies by other investigators reporting that the FAS polymorphisms are associated with increased risk of lymphoproliferative diseases and some cancers. For instance, it has been shown that increased risk for acute myeloid leukaemia, cervical cancer, and oesophageal cancer is associated with the FAS - 1377AA and/or -670GG genotype. ${ }^{24} 26{ }^{38}$ To date, only one study has been published reporting the association between the FAS polymorphism at the $-670 \mathrm{~A} / \mathrm{G}$ site and the risk of lung cancer. ${ }^{39}$ Although the $F A S-670 \mathrm{~A} / \mathrm{G}$ polymorphism was not an independent risk factor for lung cancer in their study, which is most likely due to very limited statistical power (only 68 patients and 74 controls), it appeared to modulate the risk associated with low apoptotic capacity, with the $-670 \mathrm{G}$ allele being a risk allele. These data are generally in agreement with our results in this study of a Chinese population, where the $F A S-670 \mathrm{~A} / \mathrm{G}$ polymorphism was almost completely linked with the $-1377 \mathrm{G} / \mathrm{A}$ polymorphism. Although no study except our previous one ${ }^{26}$ has reported whether the FASL polymorphism is associated with the risk of cancer, the FASL - 844CC genotype has been associated with the risk of systemic lupus erythematosus, ${ }^{25}$ an autoimmune disease characterised by accelerated FAS mediated apoptosis of lymphocytes and monocytes. Therefore, these data strongly support our hypothesis that functional polymorphisms in FAS and/or FASL may contribute to susceptibility to cancer.

We also observed a more than multiplicative gene-gene interaction between FAS and FASL polymorphisms in increasing the risk of lung cancer, suggesting that these two polymorphisms are likely to be active in the same causal pathway. This result is fairly consistent with our previous study on oesophageal SCC. ${ }^{26}$ The statistical interaction between FAS and FASL polymorphisms is biologically plausible because these two molecules are a receptor ligand system, and apoptotic cell death needs both normal FAS and normal FASL. ${ }^{40}$ Therefore, if a cell carries functional polymorphisms in both genes that have an effect on their level of expression, then a greater than additive effect is to be expected. In the development of lung cancer, transformed cells carrying the FASL -844CC genotype that express high level of FASL may create an immunoprivileged site by killing cytotoxic immune cells and thus escaping host immunosurveillance; on the other hand, reduced expression of FAS due to the FAS - 1377AA genotype may assist the transformed cells to evade FAS mediated cell death. As a result, subjects carrying both FAS - 1377AA and FASL -844CC could be at 
Table 4 Risk of lung cancer related to FAS and FASL genotypes by age and smoking status

\begin{tabular}{|c|c|c|c|c|c|c|c|c|}
\hline & \multicolumn{2}{|c|}{ FAS - 1377 genotype } & \multirow[b]{2}{*}{$\mathrm{OR}+(95 \% \mathrm{Cl})$} & \multirow[b]{2}{*}{ p valueł } & \multicolumn{2}{|c|}{ FASL -844 genotype } & \multirow[b]{2}{*}{$\mathrm{ORT}(95 \% \mathrm{Cl})$} & \multirow[b]{2}{*}{ p valuet } \\
\hline & $\overline{\mathrm{AA}^{*}}$ & $\mathbf{G G}+\mathbf{G A}^{*}$ & & & $\overline{\mathrm{CC}^{*}}$ & $\pi+\mathrm{TC}^{*}$ & & \\
\hline \multicolumn{9}{|l|}{ Smoking status } \\
\hline Nonsmoker & $52 / 80$ & $298 / 545$ & $1.23(0.83$ to 1.81$)$ & 0.306 & $224 / 303$ & $126 / 322$ & 1.84 (1.40 to 2.43 ) & $<0.001$ \\
\hline Smoker & $102 / 50$ & $548 / 595$ & $2.12(1.46$ to 3.07$)$ & $<0.001$ & $388 / 298$ & $262 / 347$ & $1.70(1.35$ to 2.14$)$ & $<0.001$ \\
\hline \multicolumn{9}{|c|}{ Pack years smoked } \\
\hline$\leqslant 20$ & $27 / 16$ & $163 / 289$ & 2.92 (1.51 to 5.66$)$ & 0.001 & $106 / 150$ & $84 / 155$ & 1.37 (0.94 to 1.98$)$ & 0.099 \\
\hline$>20$ & $75 / 34$ & $385 / 306$ & 1.84 (1.18 to 2.89$)$ & 0.008 & $282 / 148$ & 178/192 & 1.96 (1.45 to 2.64$)$ & $<0.001$ \\
\hline \multicolumn{9}{|l|}{ Histological type } \\
\hline SCC & $68 / 130$ & $380 / 1140$ & 1.73 (1.22 to 2.44$)$ & 0.002 & $274 / 601$ & $174 / 669$ & 1.78 (1.40 to 2.26$)$ & $<0.001$ \\
\hline Adenocarcinoma & $47 / 130$ & $250 / 1140$ & $1.63(1.13$ to 2.35$)$ & 0.010 & $176 / 601$ & $121 / 669$ & 1.67 (1.29 to 2.17$)$ & $<0.001$ \\
\hline Other & $39 / 130$ & $216 / 1140$ & $1.66(1.12$ to 2.47$)$ & 0.012 & $162 / 601$ & $93 / 669$ & $1.96(1.48$ to 2.61$)$ & $<0.001$ \\
\hline
\end{tabular}

higher risk for developing lung cancer than those carrying either the FAS - 1377AA or FASL -844CC alone. This speculation is consistent with the findings from direct studies on FAS/FASL expression in certain cancers, including lung cancer, showing frequent loss of FAS expression and gain of FASL expression in cancer cells. ${ }^{10-12} 4142$

A statistical interaction between FAS and FASL polymorphisms and tobacco smoking was also evident in the present study. The FAS - 1377AA genotype modulated the risk of lung cancer among smokers but not among non-smokers, suggesting a gene-environment interaction. However, among smokers, the increased risk of lung cancer associated with the FAS - 1377AA genotype was higher in light than in heavy ( $>20$ pack years in this study) smokers. This finding may reflect the fact that the genetic effect can be overwhelmed by the environmental effect. Tobacco smoking is an established causal factor for lung cancer; therefore, this interaction is biologically plausible. A higher risk of lung cancer among smokers who carried the FAS - 1377AA genotype may be attributed to many transformed or pre-invasive lung cells caused by tobacco carcinogens, which in turn increases the possibility that, owing to low FAS expression, one of these cells will evade immunosurveillance to become carcinogenic. For the FASL polymorphism, however, a significantly increased risk of lung cancer was observed in both smokers and non-smokers, and the risk among smokers was more pronounced in heavy than in light smokers. It is also rational to speculate that the presence of the FASL -844CC genotype, which is associated with increased level of FASL expression, will help transformed or preinvasive lung cells counterattack against anti-tumour immune cells and thus contribute to tumour immune escape. Moreover, because tobacco smoking can induce FASL expression, ${ }^{35}{ }^{36}$ another hypothesis for the interaction is that, in addition to higher constitutive expression resulting from the FASL - 844T/C polymorphism, smoking may induce a higher level of $F A S L$ expression from the FASL $-844 \mathrm{C}$ allele than from the FASL $-844 \mathrm{~T}$ allele. As a result, smoking and carrying the FASL -844CC genotype increase susceptibility to lung cancer. A higher risk of lung cancer associated with the FASL -844CC genotype in nonsmokers than in light smokers who smoked less than 20 pack years may be ascribed to the exposure of these non-smokers to high level of environmental smoke, because smoking is very prevalent and unlimited in public places in China. The pattern of this interaction between FAS and FASL polymorphisms and smoking in lung cancer is very similar to that observed in our previous study on oesophageal SCC, suggesting that this gene-environment interaction may have important implications in smoking related human cancer development.
Our patients may not be representative of total lung cancer patients in the study area because they were recruited from only one hospital. However, because we used incident patients, and recruited a large number of subjects, our results are unlikely to be attributable to selection bias. In addition, the genotypic frequencies of FASL - 844T/C and FAS - 1377G/ A polymorphisms observed in 1270 controls in this study are identical to those reported previously, ${ }^{26}$ further validating our results. Nevertheless, it is important to carry out multicentre case-control studies and/or population based prospective studies in different ethnic populations for comparison.

In conclusion, this case-control study with a large sample size provides the first evidence that functional FAS and FASL polymorphisms are associated with the risk of lung cancer. This association is especially noteworthy in tobacco smokers and displays a multiplicative gene-gene interaction between FAS and FASL polymorphisms. These results are consistent with our initial findings in the oesophageal SCC study, further supporting the hypothesis that FAS and FASL triggered apoptosis pathway plays an important role in human carcinogenesis.

\section{ACKNOWLEDGEMENTS}

This sutdy was supported by the National Natural Science Foundation (grant no. 39825112), the National "863" High Technology Project (grant no. 2002BA71lA06), and the State Key Basic Research Program (grant no. G1998051204).

\section{Authors' affiliations}

$X$ Zhang, X Miao, T Sun, W Tan, S Qu, P Xiong, Y Zhou, D Lin, Department of Etiology and Carcinogenesis, Cancer Institute, Chinese Academy of Medical Sciences and Peking Union Medical College, Beijing, China

X Zhang, Department of Biological Sciences, North China Coal Medical College, Tangshan, Hebei, China

P Xiong, Department of Epidemiology, University of Texas M D

Anderson Cancer Center, Houston, TX 77030, USA

Competing interests: none declared

The first two authors contributed equally to this work.

\section{REFERENCES}

1 Evan GI, Vousden $\mathrm{KH}$, Proliferation. cell cycle and apoptosis in cancer. Nature 2001;17:342-8.

2 Lowe SW, Lin AW. Apoptosis in cancer. Carcinogenesis 2000;21:485-95.

3 Tgney FH, Krammer PH. Immune escape of tumors: apoptosis resistance and tumor counterattack. J Leukocyte Biol 2002;71:907-20.

4 O'Connell J, O'Sullivan GC, Collins JK, Shanahan F. The Fas counterattack: Fas-mediated T cell killing by colon cancer cells expressing Fas ligand. J Exp Med 1996; 184:1075-82.

5 Griffith TS, Ferguson TA. The role of FasL-induced apoptosis in immune privilege. Immunol Today 1997; 18:240-4.

6 Nagata S, Golstein P. The Fas death factor. Science 1995;267:1449-56. 
7 Muschen M, Warskulat U, Beckmann MW. Defining CD95 as a tumor suppressor gene. J Mol Med 2000;78:312-25.

8 Suda T, Takahashi T, Golstein P, Nagata S. Molecular cloning and expression of the Fas ligand, a novel member of the tumor necrosis factor family. Cell 1993:75: 1169-78.

9 Lee SH, Shin MS, Park WS, Kim SY, Dong SM, Pi JH, Lee HK, Kim HS, Jang J J Kim CS, Kim SH, Lee JY, Yoo NJ. Alterations of Fas (Apo-1/CD95) gene in transitional cell carcinomas of urinary bladder. Cancer Res 1999;27:3068-72.

10 Gartas C, Tohmoa Y, Barnas C, Taniere P, Hainaut P, Ohgaki H. Upregulation of Fas (APO-1/CD95) ligand and down-regulation of Fas expression in human esophageal cancer. Cancer Res 1998;58:2057-62.

11 Gastman BR, Atarshi Y, Reichert TE, Saito T, Balkir L, Rabinowich $\mathrm{H}$, Whiteside TL. Fas ligand is expressed on human squamous cell carcinomas of the head and neck, and it promotes apoptosis of T lymphocytes. Cancer Res 1999;59:5356-64.

12 Viard-Leveugle I, Veyrenc S, French LE, Brambilla C, Brambilla E. Frequent loss of Fas expression and function in human lung tumors with overexpression of FasL in small cell lung carcinoma. J pathol, 2003;201:268-77.

13 Lee SH, Shin MS, Park WS, Kim SY, Kim HS, Han JY, Park GS, Dong SM, $\mathrm{Pi} \mathrm{JH}$, Kim CS, Kim SH, Lee JY, Yoo NJ. Alterations of Fas (Apo-1/CD95) gene in non-small cell lung cancer. Oncogene 1999:18:3754-60.

14 Niehans GA, Brunner T, Frizelle SP, Liston JC, Salerno CT, Knapp DJ, Green DR, Kratzke RA. Human lung carcinomas express Fas ligand. Cancer Res 1997; 57:1007-12.

15 Bennett MW, O'Connell J, O'Sullivan GC, Brady C, Roche D, Collins JK, Shanahan $F$ The Fas counterattack in vivo: apoptotic depletion of tumorinfiltrating lymphocytes associated with Fas ligand expression by human esophageal carcinoma. J Immunol 1998;160:5669-75.

16 von Bernstorff W, Spanjaard RA, Chan AK, Lockhart DC, Sadanaga N, Wood I, Peiper M, Goedegebuure PS, Eberlein TJ. Pancreatic cancer cells can evade immune surveillance via nonfunctional Fas (APO-1/CD95) receptors and aberrant expression of functional Fas ligand. Surgery 1999;125:73-84

17 Koyama S, Koike N, Adachi S. Fas receptor counterattack against tumorinfiltrating lymphocytes in vivo as a mechanism of immune escape in gastric carcinoma. J Cancer Res Clin Oncol 2001;127:20-6.

18 Davidson WF, Giese T, Fredrickson TN. Spontaneous development of plasmacytoid tumors in mice with defective Fas-Fas ligand interactions. J Exp Med 1998; 187:1825-8.

19 Peters AM, Kohfink B, Martin H, Griesinger F, Wormann B, Gahr M, Roesler J. Defective apoptosis due to a point mutation in the death domain of CD95 associated with autoimmune lymphopproliferative syndrome, T-cell lymphoma, and Hodgkin's disease. Exp Hematol 1999;27:868-74.

20 Lee SH, Shin MS, Park WS, Kim SY, Dong SM, Pi JH, Lee HK, Kim HS, Jang J , Kim CS, Kim SH, Lee JY, Yoo NJ. Alterations of Fas (Apo-1/CD95) gene in transitional cell carcinomas of urinary bladder. Cancer Res 1999;27:3068-72.

21 Lee SH, Shin MS, Park WS, Kim SY, Kim HS, Han JY, Park GS, Dong SM, $\mathrm{Pi} J \mathrm{H}, \mathrm{Kim}$ CS, Kim SH, Lee JY, Yoo NJ. Alterations of Fas (Apo-1/CD95) gene in non-small cell lung cancer. Oncogene 1999;18:3754-60.

22 Takahashi T, Tanaka M, Brannan Cl, Jenkins NA, Copeland NG, Suda T, Nagata S. Generalized lymphoproliferative disease in mice, caused by a point mutation in the Fas ligand. Cell 1994;76:969-76.

23 Huang QR, Morris D, Manolios N. Identification and characterization of polymorphisms in the promoter region of the human Apo-1/Fas (CD95) gene. Mol Immunol 1997;34:577-82.
24 Sibley K, Rollinson S, Allan JM, Smith AG, Law GR, Roddam PL, Skibola CF, Smith MT, Morgan GJ. Functional FAS promoter polymorphisms are associated with increased risk of acute myeloid leukemia. Cancer Res 2003;63:4327-30

25 Wu J, Metz C, Xu X, Abe R, Gibson AW, Edberg JC, Cooke J, Xie F Cooper GS, Kimberly RP. A novel polymorphic CAAT/enhancer-binding protein $\beta$ element in the FasL gene promoter alters Fas ligand expression: a candidate background gene in African American systemic lupus erythematosus patients. J Immunol 2003;170:132-8.

26 Sun T, Miao X, Zhang X, Tan W, Xiong P, Lin D. Polymorphisms of death pathway genes FAS and FASL in esophageal squamous cell carcinoma. J Natl Cancer Inst 2004;96:1030-6.

27 Yang L, Parkin DM, Li L, Chen Y. Time trend in cancer mortality in China Int J Cancer 2003;106:771-83.

28 Chen ZM, Xu Z, Collis R, Li WY, Peto R. Early health effects of the emerging tobacco epidemic in China. A 16-years prospective study. JAMA 1997;278:1500-4.

29 Liu BQ, Peto R, Chen ZM, Boreham J, Wu YP, Li JY, Campbell TC, Chen JS Emerging tobacco hazards in China. 1. Retrospective proportional mortality study of one million deaths. Br Med J 1998;317:1411-22.

30 Ferlay J, Bray F, Pisani P, Parkin DM. Globocan 2000: cancer incidence, mortality and prevalence worldwide, version 1.0. IARC Cancer Base No. 5 Lyon: IARC Press, 2001

31 Kleinerman R, Wang Z, Lubin J, Zhang S, Metayer C, Brenner A. Lung cancer and indoor air pollution in rural China. Ann Epidemiol 2000;10:469.

32 Metayer C, Wang Z, Kleinerman RA, Wang L, Brenner AV, Cui H, Cao J, Lubin JH Cooking oil fumes and risk of lung cancer in women in rural Gansu, China. Lung Cancer 2002;35:111-17.

33 Liang G, Xing D, Miao X, Tan W, Yu C, Lu W, Lin D. Sequence variations in the DNA repair gene XPD and risk of lung cancer in a Chinese population. Int J Cancer 2003; 105:669-73.

34 In: Kleinbaum DG, Kupper LL, Morgenstern H, eds. Epidemiologic research principles and quantitative methods. London: Lifetime Learning Publications, 1982.

35 Suzuki N, Wakisaka S, Takeba Y, Mihara S, Sakane T. Effects of cigarette smoking on Fas/Fas ligand expression of human lymphocytes. Cell Immunol 1999;25:48-53.

36 Bijl M, Horst G, Limburg PC, Kallenberg CG. Effects of smoking on activation markers, Fas expression and apoptosis of peripheral blood lymphocytes. Eur J Clin Invest 2001;31:550-3.

37 Pugh BF, Tjian R. Mechanism of transcriptional activation by $\mathrm{Sp} 1$ : evidence for coactivators. Cell 1995:61:1187-97.

38 Lai HC, Sytwu HK, Sun CA, Yu MH, Yu CP, Liu HS, Chang CC, Chu TY. Single nucleotide polymorphism at Fas promoter is associated with cervical carcinogenesis. Int J Cancer 2003; 103:221-5

39 Wang LE, Cheng L, Spitz MR, Wei Q. Fas A670G polymorphism, apoptotic capacity in lymphocyte cultures, and risk of lung cancer. Lung Cancer 2003:42: 1-8.

40 Krammer PH. CD95's deadly mission in the immune system. Nature 2000;407:789-95

41 Koyama S, Koike N, Adachi S. Fas receptor counterattack against tumorinfiltrating lymphocytes in vivo as a mechanism of immune escape in gastric carcinoma. J Cancer Res Clin Oncol 2001;127:20-6.

42 Bernstorff WV, Glickman JN, Odze RD, Farraye FA, Joo HG, Goedegebuure PS, Eberlein TJ. Fas (CD95/APO-1) and Fas ligand expression in normal pancreas and pancreatic tumors. Implications for immune privilege and immune escape. Cancer 2002;94:2552-60. 